\title{
Field measurements of gasoline direct injection emission factors: spatial and seasonal variability
}

\author{
Naomi Zimmerman, Jonathan M. Wang, Cheol-Heon Jeong, \\ Manuel Ramos, Nathan Hilker, Robert M. Healy, Kelly \\ Sabaliauskas, James S. Wallace, and Greg J. Evans
}

\begin{abstract}
Version Post-print/accepted manuscript
Citation Zimmerman, N., Wang, J. M., Jeong, C. H., Ramos, M., Hilker, N., (published version) Healy, R. M., ... \& Evans, G. J. (2016). Field measurements of gasoline direct injection emission factors: spatial and seasonal variability. Environmental science \& technology, 50(4), 2035-2043.

Publisher's Statement This document is the Accepted Manuscript version of a Published Work that appeared in final form in Environmental Science and Technology, copyright (C) American Chemical Society after peer review and technical editing by the publisher. To access the final edited and published work see 10.1021/acs.est.5b04444.
\end{abstract}

How to cite TSpace items

Always cite the published version, so the author(s) will receive recognition through services that track citation counts, e.g. Scopus. If you need to cite the page number of the author manuscript from TSpace because you cannot access the published version, then cite the TSpace version in addition to the published version using the permanent URI (handle) found on the record page.

This article was made openly accessible by $U$ of $T$ Faculty. Please tell us how this access benefits you. Your story matters. 


\section{Field measurements of gasoline direct injection}

\section{2 emission factors: spatial and seasonal variability}

3 Naomi Zimmerman, ${ }^{\dagger}$ Jonathan M. Wang, ${ }^{\dagger}$ Cheol-Heon Jeong, ${ }^{\dagger}$ Manuel Ramos, ${ }^{\dagger}$

4 Nathan Hilker,${ }^{\dagger}$ Robert M. Healy,${ }^{\dagger}$ Kelly Sabaliauskas, ${ }^{\dagger}$ James S. Wallace, ${ }^{\ddagger}$ Greg J. Evans ${ }^{\dagger}, *$

5 Department of Chemical Engineering and Applied Chemistry, University of Toronto, Toronto,

6 Ontario M5S3E5 Canada

$7 \quad$ Department of Mechanical and Industrial Engineering, University of Toronto, Toronto, Ontario

8 M5S3G8 Canada

9 Corresponding author:

10 Dr. Greg J. Evans

11 Dept. of Chemical Engineering and Applied Chemistry

12 University of Toronto

13200 College Street, Room 127, Toronto, Canada, M5S 3E5

14 Tel. 416-978-1821

15 Fax. 416-978-8605

16 Email: greg.evans@utoronto.ca

17

18

19 Gasoline direct injection, real-world, fuel-based, vehicle, emission factors, ultrafine particles,

20 black carbon, volatility, size distribution 

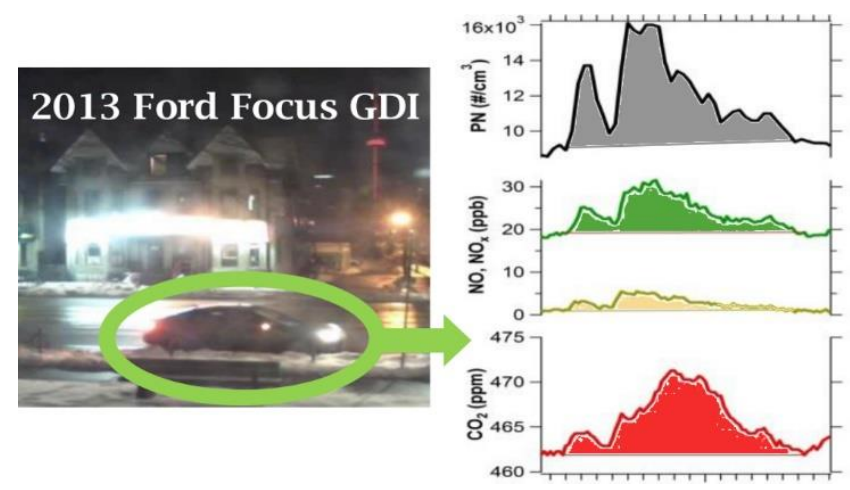

\section{ABSTRACT}

25 Four field campaigns were conducted between February 2014 and January 2015 to measure

26 emissions from light-duty gasoline direct injection (GDI) vehicles (2013 Ford Focus) in an urban

27 near-road environment in Toronto, Canada. Measurements of $\mathrm{CO}_{2}, \mathrm{CO}, \mathrm{NO}_{\mathrm{x}}$, black carbon (BC),

28 benzene, toluene, ethylbenzene-xylenes (BTEX), and size-resolved particle number (PN) were

29 recorded $15 \mathrm{~m}$ from the roadway and converted to fuel-based emission factors (EFs). Other than

30 for $\mathrm{NO}_{\mathrm{x}}$ and $\mathrm{CO}$, the GDI engine had elevated emissions compared to the Toronto fleet, with $\mathrm{BC}$

31 and BTEX EFs in the $80-90^{\text {th }}$ percentile, and PN EFs in the $75^{\text {th }}$ percentile during wintertime

32 measurements. Additionally, for three campaigns, a second platform for measuring $\mathrm{PN}$ and $\mathrm{CO}_{2}$

33 was placed 1.5-3 m from the roadway to quantify changes in PN with distance from point of

34 emission. GDI vehicle PN EFs were found to increase by up to $240 \%$ with increasing distance

35 from the roadway, predominantly due to an increasing fraction of sub-40 nm particles. PN and BC

36 EFs from the same engine technology were also measured in the laboratory. BC EFs agreed within

$3720 \%$ between the laboratory and real-world measurements; however, laboratory PN EFs were an

38 order of magnitude lower due to exhaust conditioning. 


\section{INTRODUCTION}

40 In the United States, the Corporate Average Fuel Economy (CAFE) standards have specified a

41 minimum fuel economy of $37.8 \mathrm{mpg}$ by $2016^{1,2}$, with similar fuel economy regulations set in

42 Canada and Europe. The CAFE standard will continue to increase by 5\% per year until 2025, when

43 minimum fuel economy must exceed $55 \mathrm{mpg}$. In response to these stringent regulatory

44 requirements on passenger vehicle fuel economy, automobile manufacturers have been

45 increasingly turning to gasoline direct injection (GDI) engines, which offer up to a $25 \%$

46 improvement in fuel economy compared to port fuel injection (PFI) engines ${ }^{3}$. Market share of GDI

47 vehicles is increasing rapidly; between model years 2009 and 2014 there was a ten-fold increase

48 in GDI engine sales ${ }^{4}$, and it is projected that in 2016 the market share of new light-duty vehicles

49 with this technology will exceed $50 \% 5$.

51 Compared to PFI-equipped vehicles, GDI-equipped vehicles emit substantially more particulate

52 matter $(\mathrm{PM})^{6-9}$ due to incomplete fuel volatilization causing fuel impingement on cylinder and

53 piston surfaces and incomplete fuel mixing with air resulting in pockets of fuel rich combustion.

54 Particle size distributions from GDI engine exhaust have generally been observed to be either

55 bimodal $^{10-13}$, unimodal ${ }^{9,14-16}$, or vary ${ }^{7,17}$ depending on factors such as engine operation, ethanol

56 fuel content, and fuel injection system. Of the observed bimodal size distributions, the smaller

57 mode is typically $<25 \mathrm{~nm}$ and has been proposed to be dominated by soot cores ${ }^{11,18}$ or semi-volatile

58 nucleation particles ${ }^{13,19}$; however, their composition remains highly uncertain. There is stronger

59 consensus that the larger mode, typically $40-100 \mathrm{~nm}$, is composed of agglomerated soot particles

60 with adsorbed semi-volatile material that has condensed. 
62 Accurately characterizing GDI PM also presents a measurement challenge; compared to diesel,

63 the large aromatic fraction in gasoline is expected to produce PM with a larger organic mass

64 fraction and with higher volatility ${ }^{20-22}$. As such, GDI PM mass loadings and chemical composition

65 may vary depending on the measurement environment or exhaust conditioning. For example, two

66 laboratory measurements of GDI organic carbon (OC) using the same measurement technique but

67 different dilution systems resulted in measured organic carbon mass fractions (OC:PM ratios)

68 ranging from $<0.25$ to $0.57^{9,23}$.

69

70 Recent computational fluid dynamic models of diesel exhaust behaviour in exhaust plumes have

71 suggested that as the plume dilutes in the "tailpipe-to-road" region, the combination of sulfuric

72 acid, water vapor, condensable organics and soot particles results in rapidly growing particles

73 within the exhaust plume. ${ }^{24-26}$ This growth may also occur in GDI exhaust plumes, since particle

74 number (PN) emissions have been shown to be influenced by sulfur content in lubricating oil ${ }^{27}$,

75 but the time scales for these growth processes are unknown and this effect has not yet been directly

76 measured. Given the projected increase in GDI vehicle market share in the coming years, an

77 improved understanding of the characteristics and variability of GDI emissions in both laboratory

78 and real-world near-road environments is needed to guide legislation and support emissions

79 models and inventories. Additionally, gas phase organic emissions from gasoline vehicles are

80 known precursors to secondary organic aerosol (SOA) in urban areas ${ }^{28-30}$, thus measuring GDI

81 emissions in near-road environments may contribute to our understanding of how GDI vehicles

82 impact PM in urban environments. 
84 In this study, GDI emissions, expressed as fuel-based emission factors (EFs), were evaluated in an

85 urban near-road environment during four campaigns conducted between February 2014 and

86 January 2015 spanning a broad range of meteorological conditions. PN EFs were also measured

87 at distances ranging from 1.5-15 $\mathrm{m}$ from the roadway to quantify spatial variability. Additionally,

88 particle number (PN) and black carbon (BC) EFs were compared to laboratory measurements

89 performed in a manner similar to the European Union Particle Measurement Program (PMP) ${ }^{31}$

90 (i.e., removal of volatile fraction through heated dilution) to quantify the differences between the

91 two measurement environments.

\section{2. METHODS}

\section{$94 \quad 2.1 \quad$ Measurement Site}

95 Emission factor measurements were made during four campaigns carried out between February 962014 and January 2015 at the Southern Ontario Centre for Atmospheric Aerosol Research

97 (SOCAAR) Field Measurement Facility in downtown Toronto, Canada. The sampling site is 98 located north of a four-lane roadway that experiences relatively high traffic volumes ranging from

$9916,000-25,000$ cars per day ${ }^{32}$. Due to the high traffic volumes, all measurements were taken from

$1003: 00 \mathrm{AM}-6: 00 \mathrm{AM}$ when traffic volume was at a minimum to isolate the signal from the GDI

101 vehicle and eliminate the effects of photochemistry. Measurements were taken across a total of 11

102 days and grouped by season: winter 2014, spring 2014, summer 2014, and winter 2015. During

103 each set of measurements, wind speed, wind direction, temperature, and relative humidity were

104 also recorded concurrently with a Vaisala WXT520 Weather Transmitter located $3 \mathrm{~m}$ above

105 ground. The measurement campaigns captured a broad range of meteorological conditions, with 
106 temperatures and relative humidity ranging from $-7.5^{\circ} \mathrm{C}$ to $+17.5^{\circ} \mathrm{C}$ and 53.2 to $93.7 \%$,

107 respectively. Specific details of measurement dates, times, and meteorological conditions are 108 provided in the Supporting Information.

\section{$\begin{array}{lll}110 & 2.2 & \text { Field research vehicles and operation }\end{array}$}

111 Field measurements were taken from 2013 Ford Focus light-duty SE sedans equipped with 112 gasoline direct injection (GDI) engines fuelled with commercially-available gasoline. A single

113 vehicle model was used as a control to explore the impacts of season, meteorology, vehicle 114 operation, and distance from roadway on emissions. While measurements from additional GDI115 equipped vehicles would be beneficial, this was outside the scope of this specific study and will 116 be explored in future work. The vehicles were rented from a local car sharing service. To ensure

117 emissions from the vehicle were not affected by poor engine tuning or the need for vehicle 118 maintenance, a total of seven unique 2013 Ford Focus vehicles were used across the 11 119 measurement days. For the winter 2014 and spring 2014 campaigns a 2000 Honda CR-V equipped 120 with a PFI engine was also deployed to compare GDI and PFI PN emissions. The vehicles were 121 operated under three conditions: 1) engine idle, 2) cruising at $40 \mathrm{~km} / \mathrm{h}$, and 3) acceleration from $12220 \mathrm{~km} / \mathrm{h}$ to $50 \mathrm{~km} / \mathrm{h}$. Emissions from braking were not considered due to the possibility of PN 123 emissions occurring independent of $\mathrm{CO}_{2}$ emissions. ${ }^{33}$ Vehicle speed and location were recorded 124 with an on-board diagnostics (OBD2) data logger (Mini ELM327 V1.5) and driveway reflector 125 rods were installed at the roadside to ensure the vehicle was stopping, starting, and idling at a 126 consistent location across all measurement days. Prior to recording any emissions from the test 127 vehicles, the vehicles were warmed up for a minimum of 20 minutes. During the measurement 
128 periods, the vehicles remained on at all times to ensure the engine remained at its set operating

129 temperature. Emissions measured from City of Toronto garbage trucks (predominantly diesel fleet)

130 passing the measurement site during the campaigns were also recorded. A graphical representation

131 of the measurement site is provided in the Supporting Information (Figure S1).

\section{$133 \quad 2.3 \quad$ Measurement Techniques}

134 A detailed description of the instrumentation at the SOCAAR field measurement facility has been

135 reported previously ${ }^{32}$, but is summarized briefly here. At the SOCAAR measurement site ("near-

136 road site"), inlets sampling ambient air were located $15 \mathrm{~m}$ from the roadway and $3 \mathrm{~m}$ above ground

137 to measure $\mathrm{NO}, \mathrm{NO}_{\mathrm{x}}, \mathrm{CO}, \mathrm{CO}_{2}$ (Thermo Scientific 42i, 48C, and 410i), benzene, toluene, and

138 ethylbenzene-xylenes (BTEX, IONICON Analytik PTR-TOF-MS), particle number (PN)

139 concentration (TSI CPC 3788) and size distribution (TSI FMPS 3090), and black carbon (BC,

140 Droplet Measurement Technologies PASS-3). For the spring 2014, summer 2014, and winter 2015

141 measurement campaigns, a second measurement station to measure $\mathrm{CO}_{2}$ and $\mathrm{PN}$ concentration and

142 size distribution was constructed $3 \mathrm{~m}$ from the roadway and $1 \mathrm{~m}$ above ground ("roadside site") to

143 measure any spatial variability in particle phase emissions during plume dilution. During the

144 winter 2015 campaign, a $1.5 \mathrm{~m}$ inlet line was added to the secondary measurement station and

145 extended forwards enabling an additional measurement $1.5 \mathrm{~m}$ from the roadway. A summary of 146 the instrumentation and deployment is provided in the Supporting Information.

\section{$148 \quad 2.4 \quad$ Data Analysis}

149 The algorithm and validation protocols developed in Wang et al. ${ }^{32}$ were applied in IGOR Pro v6.34

150 to automatically identify vehicle exhaust plumes based on inflection points in the $\mathrm{CO}_{2}$ time series 
151 and to calculate vehicle EFs. As part of this protocol, pollutant signals were time synchronized,

152 and we considered only plumes with a minimum time-integrated peak area of $20 \mathrm{mg} \mathrm{C}-\mathrm{s} \mathrm{m}-3$.

153 Plumes shorter than $10 \mathrm{~s}$ or with an average carbon content less than $2 \mathrm{mg} \mathrm{C} \mathrm{m}^{-3}$ were rejected.

154 Instrument sensitivities were calculated from the measured signal during vehicle-free periods.

155 Measured plumes with pollutant signals below this sensitivity (i.e., $\mathrm{CO}_{2}$ signal but no significant

156 pollutant signal) were classified as "below threshold" (BT) and were calculated using the effective

157 sensitivity in the numerator of Equation (1). A detailed discussion of calculating instrument

158 sensitivity and applying instrument sensitivity to EF calculations is provided in Wang et al. ${ }^{32}$ For

159 above threshold (AT) pollutant signals, fuel-based EFs were calculated according to Equation (1).

$$
\mathrm{EF}_{\mathrm{P}}=\left(\frac{\Delta[\mathrm{P}]}{\Delta\left[\mathrm{CO}_{2}\right]+\Delta[\mathrm{CO}]}\right) w_{\mathrm{C}}
$$

161 Where $\mathrm{EF}_{\mathrm{P}}$ is the fuel-based emission factor of pollutant $\mathrm{P}$ (in $\mathrm{g}, \mathrm{mg}$, or particle number) per $\mathrm{kg}$ of

162 fuel burned assuming ambient conditions $\left(25^{\circ} \mathrm{C}, 101.325 \mathrm{kPa}\right)$. In equation $(1), \Delta \mathrm{P}, \Delta \mathrm{CO}_{2}$, and

$163 \Delta \mathrm{CO}$ are the background subtracted concentrations integrated across the plume duration, and $\mathrm{w}_{\mathrm{c}}$ is

164 the weight fraction of carbon in gasoline fuel (assumed $\left.\mathrm{w}_{\mathrm{c}}=0.86\right) .{ }^{34}$ For the "roadside site" no CO

165 measurement was available, and as such the CO term was removed from equation (1); however,

166 the bulk of the fuel carbon is assumed to be converted to $\mathrm{CO}_{2}$ and the calculated $\mathrm{CO}_{2}: \mathrm{CO}$ ratio at

167 the near-road site exceeded 1000. Additionally, the GDI vehicles were recent models all with very

168 low mileage $(<50,000 \mathrm{~km})$ expected to produce a very low CO signal because of the young catalyst.

169 While the Honda CR-V was not a recent model, near-road (15 m) CO emissions were detected 170 from less than $30 \%$ of the plumes at levels at or below the fleet average calculated in Wang et al. ${ }^{32}$

172 Prior to calculating emission factors, some post-processing of the particle number and size 173 distribution measurements was performed. As measurements of vehicle exhaust with an FMPS or 
174 EEPS instrument have been shown to result in over counting of PN and misclassification of particle

175 size $^{35}$, the correction protocol described in Zimmerman et al. ${ }^{36}$ was applied here. Additionally,

176 the data were corrected for line losses, thermodenuder transmission efficiency (where applicable),

177 and differences in CPC cut-off diameters. Further information on the instrument time resolution,

178 detection limits, and data correction are included in the Supporting Information.

$180 \quad 2.5 \quad$ Laboratory Measurement of Particle Phase Emissions

181 Elemental carbon (EC) and PN EFs were also calculated from laboratory measurements taken

182 using a 2012 Ford Focus 2.0L displacement wall-guided naturally aspirated GDI engine coupled

183 to an engine dynamometer. While the laboratory engine was one model year older than the vehicles

184 used for the real-world testing, they are nominally the same engine. The laboratory engine was

185 operated at a steady-state highway cruise condition ( $2600 \mathrm{rpm}, 41 \mathrm{ft}-\mathrm{lb})$ representative of highway

186 driving at approximately $100 \mathrm{~km} / \mathrm{h}$ in top gear. The engine was fuelled with commercially-

187 available premium gasoline (91 anti-knock index / 95 research octane number) containing no

188 ethanol, denoted E0, and commercially-available premium gasoline splash blended with

189 anhydrous ethanol to make a 10\% (v/v) ethanol blend, denoted E10. An E10 fuel was tested

190 because in Ontario, regular gasoline (87 anti-knock index) must contain at least 5\% (v/v) ethanol ${ }^{37}$,

191 with many suppliers selling fuel containing up to $10 \%(\mathrm{v} / \mathrm{v})$ ethanol.

192 Details of engine operation, tests fuels, a schematic of the engine laboratory sampling 193 configuration, details of the thermal-optical transmittance protocol and calculation of EC 194 concentration, and details of EF calculations with the laboratory data set is provided in the 195 Supporting Information. 


\section{RESULTS AND DISCUSSION}

\subsection{Emission Factor Detection and Classification}

198 Plume capture was defined based on total $\mathrm{CO}_{2}$ within the plume. If a pollutant concentration in a 199 captured plume was below the effective instrument thresholds (see Table S3, Supporting 200 Information) then the pollutant EF was designated "below threshold" (BT). Across the 201 measurement campaigns, a plume was captured (i.e., $\mathrm{CO}_{2}$ signal detected) at the near-road (15 m) 202 and roadside $(3 \mathrm{~m})$ sites $46 \%$ and $71 \%$ of the time the GDI vehicle passed the site, respectively.

203 This amounted to a total of 93 plumes detected at the near-road site and 61 plumes at the roadside 204 site. The absolute number of captured roadside plumes was less than near-road plumes as the 205 roadside site was not deployed during the winter 2014 campaign. The percentage of plumes below 206 threshold varied by pollutant, but in general ranged from 20-40\% for $\mathrm{NO}_{\mathrm{x}}, \mathrm{PN}, \mathrm{BC}$, and VOCs and 207 ranged from $65-90 \%$ for CO. From the meteorological data, EFs were only detected when ground 208 level winds were blowing towards the inlet, which was located north of the roadway. A summary 209 of capture rate by pollutant and by driving condition, and the wind rose of detected plumes is 210 provided in the Supporting Information.

211 Seasonal differences in EFs were found to be of greater significance than differences in vehicle

212 operation and vehicle ID, thus EFs were averaged across all driving conditions. A Welch's two213 sided t-test for differences between driving conditions (see Supporting Information, Table S7)

214 indicated that differences in emission factors by driving condition were largely statistically 215 insignificant. While there is consensus that driving condition should impact vehicle emission 216 factors, the small sample size for each driving condition and high degree of variability from the 217 single vehicle real-world measurement method did not allow for a meaningful assessment of the 
218 impact of vehicle operation. Additionally, there was little difference in the shape of the plume-

219 averaged particle size distributions for each of the vehicle operating conditions (provided in the 220 Supporting Information).

\section{$221 \quad 3.2 \quad$ Emission Factors at the Near-Road $(15 \mathrm{~m})$ Site}

222 The above threshold and combined (above threshold and below threshold) EFs from the near-road

223 (15 m) site were averaged seasonally. Pollutants which varied seasonally included PN and BTEX,

224 whereas $\mathrm{NO}_{x}, \mathrm{CO}$, and $\mathrm{BC}$ showed no distinct seasonality (Welch's t-test $\mathrm{p}>0.1$, all $\mathrm{p}$-values

225 reported in Supporting Information). Furthermore, CO was not detected in significant quantities

226 in the GDI exhaust, as expected for a relatively new vehicle with a young catalyst.

228 The combined PN EFs ranged from $4.13-11.3 \times 10^{14}$ particles $\mathrm{kg}^{-}-\mathrm{fuel}^{-1}$ and were inversely 229 correlated with outdoor air temperature; average near-road (15 m) PN EFs in winter 2015 were 2.7

230 and 1.8 times larger than the EFs measured in spring and summer 2014, respectively. Average

231 temperature vs. average PN EF is provided in the Supporting Information. Cooler outdoor

232 temperature may impact PN emissions in two ways: increased gas-to-particle partitioning of low

233 volatility gases ${ }^{38-40}$ and a prolonged cold start condition increasing PN emissions ${ }^{7,41,10}$. An

234 exception to this trend was observed during the summer 2014 campaign. While temperatures

235 during the summer 2014 campaign exceeded those during the spring 2014 campaign, the detected

236 PN EFs were $48 \%$ higher in summer 2014. This is potentially due to the seasonal changes in fuel

237 formulation (i.e., summer grade vs winter grade) to achieve a target Reid vapor pressure. In 238 summer grade fuel, the volatility is reduced by replacing n-butane with heavier alkanes and 239 aromatic hydrocarbons including toluene. ${ }^{42,43}$ Increasing gasoline fuel aromatic content has been 
240 shown to increase soot formation in engine laboratory studies. For example, doping commercially-

241 available fuel with $10 \%$ toluene resulted in a $112 \%$ increase in $\mathrm{BC}$ concentration ${ }^{44}$ and increasing

242 fuel aromatic content from $15 \%$ to $25 \%$ resulted in a $78 \%$ and $169 \%$ increase in BC and PN

243 emissions, respectively. ${ }^{45}$ In this study, BTEX emissions, especially ethylbenzene-xylenes, were

244 elevated in the exhaust in summer 2014 relative to spring 2014 and above detection threshold

245 levels of toluene were detected in the plumes $20 \%$ more often relative to other seasons (see

246 Supporting Information).The broad range of BTEX emissions likely reflects variability in the

247 aromatics found in commercial gasoline blends, which vary by supplier and season. The test

248 vehicles came pre-fuelled, thus variability is expected to be maximized.

250 Figure 1 shows the GDI vehicle EFs overlaid on a cumulative probability distribution of the

251 Toronto fleet EFs from the same measurement site originally reported in Wang et al. ${ }^{32}$ from four

252 month-long continuous campaigns performed between November 2013 and September 2014. For

$253 \mathrm{NO}_{\mathrm{x}}$, the campaign-averaged EFs from the GDI were in line with the Toronto fleet average (NOx:

$25452^{\text {nd }}$ percentile of the fleet). Compared to the Toronto fleet, on average the GDI vehicle produced

255 PN emission factors in the $52^{\text {nd }}$ percentile of the fleet; however, this varied by season (range: $45^{\text {th }}$

256 percentile in spring 2014 to $75^{\text {th }}$ percentile in winter 2015). For BC, compared to the Toronto fleet

257 the campaign-averaged GDI vehicle EFs were in the $85^{\text {th }}$ percentile, suggesting that as GDI

258 vehicles penetrate the market, ambient BC levels may rise substantially. As of late 2014, only $17 \%$

259 of the Toronto fleet had detectable $\mathrm{BC}$ emissions ${ }^{32}$, and these emissions have been largely

260 attributed to heavy-duty diesel vehicles. Within the above detection threshold fleet emissions, the

261 GDI vehicle BC EFs were in the $18^{\text {th }}$ percentile, suggesting that the GDI vehicle has BC emissions

262 slightly lower than the on-road diesel fleet. This is in agreement with laboratory studies, which 
263 have measured BC EFs from diesel vehicles as 3-7 times higher than GDI vehicles ${ }^{46-51}$. However,

264 as the share of on-road diesel vehicles with diesel particulate filters increases, it is expected that

265 GDI vehicles may become the dominant source of ambient BC and PN. The BTEX EFs from the

266 GDI vehicle were also substantially higher compared to the Toronto fleet (range: $58^{\text {th }}$ to $98^{\text {th }}$

267 percentile) suggesting that GDI vehicles may also increase ambient BTEX levels; these species

268 are soot precursors and may be incomplete combustion products from the vehicle. Furthermore,

269 fuel-rich operation during vehicle transients or fuel-rich pockets within the cylinder, noted issues

270 with GDI vehicles ${ }^{10,52,53}$, have been shown to increase BTEX emissions ${ }^{54}$, potentially explaining

271 the elevated emissions relative to the Toronto fleet. An important caveat to this analysis is that

272 both Toronto fleet and GDI vehicle EFs were calculated on a fuel burned basis. On a distance

273 travelled basis, the relative impact of GDI emissions would be reduced due to the improvement in

274 fuel economy. For example, by comparing the reported city driving fuel economies of first

275 generation (2004, PFI), second generation (2008, PFI) and third generation (2013, GDI) Ford

276 Focus vehicles, it can be estimated that replacing a first generation and second generation Ford

277 Focus with a third generation GDI vehicle would result in a $23 \%$ and $13 \%$ improvement in city

278 driving fuel economy, respectively ${ }^{55-57}$. However, the observed increases in BC, BTEX, and in

279 some seasons PN with the GDI vehicle used in this study relative to the current Toronto fleet is

280 expected to outweigh the benefits from improved fuel economy.

\section{$282 \quad 3.3 \quad$ Near-road vs. Roadside Particle Number Emission Factors}

283 For the GDI vehicle, PN emission factors were found to exhibit a strong degree of spatial

284 variability. Mean PN EFs at $15 \mathrm{~m}$ from the roadway were up to $300 \%$ higher than EFs at $1.5 \mathrm{~m}$

285 from the roadway (Figure 2). This micro-scale spatial variability was highest in the winter and 
smallest in the summer, indicating that the relative increase in particle emissions is influenced by

287 ambient temperature. In comparison, based on the spring 2014 campaign measurements of the port

288 fuel injected CRV, the average PN EFs exhibited less spatial variability, with mean PN EFs $15 \mathrm{~m}$

289 from the roadway 17\% lower than those measured $3 \mathrm{~m}$ from the roadway (all PN EFs are available

290 in the Supporting Information).

291 The EFs in Figure 2 are average values across all driving and meteorological conditions, and thus

292 the confidence intervals are large due to the range of PN EFs measured. To further explore the 293 micro-scale spatial variability, the ratio of the PN EFs at $15 \mathrm{~m}$ and $3 \mathrm{~m}$ was calculated on a plume-

294 by-plume basis for the spring 2014, summer 2014, and winter 2015 measurement campaigns

295 (Figure 3). Only plumes where PN emissions were above the detection threshold at both the

296 roadside site and then subsequently the near-road site were considered. To determine if spatial

297 variability in PN emissions in the near-road environment was unique to GDI PM, plume-by-plume

298 ratios were also calculated for the PFI vehicle in spring 2014 and for detected garbage truck plumes

299 across all the measurement campaigns; garbage trucks are predominantly diesel vehicles which

300 typically emit a strong PN signal.

302 On a plume-by-plume basis, GDI PN EFs were $130-240 \%$ higher $15 \mathrm{~m}$ than $3 \mathrm{~m}$ from the 303 roadside, depending on season. Differences were at a minimum during the summer campaign 304 (warmest campaign) and at a maximum during the winter 2015 campaign (coldest campaign) 305 indicating that condensation may play an important role in GDI exhaust PM dynamics. In the near$306 \operatorname{road}(15 \mathrm{~m})$ region, nucleation, condensation/evaporation, coagulation, and pollutant dilution may 307 all affect the measured PN EF at different distances from the roadway. $\mathrm{As}^{\mathrm{CO}_{2}}$ and particles have 308 different diffusion coefficients, assuming PN EFs are constant in the near-road environment 
309 requires advection to be the dominant mass transport process. This was verified by calculating

310 Peclet numbers for wind speeds ranging from $0.25-10 \mathrm{~m} / \mathrm{s}$ and for $1.5-15 \mathrm{~m}$ from the roadway

311 (details in Supporting Information). In all cases, Peclet numbers were several orders of magnitude

312 above unity, indicating that advection is indeed dominant and spatial/temporal changes in PN EFs

313 are likely due to chemical or physical processing of the exhaust aerosol in the atmosphere.

314 Additionally, for the garbage trucks and the PFI vehicle, no spatial variability was observed, i.e.,

315 differences in PN emission factors at 3 and $15 \mathrm{~m}$ were statistically insignificant using a Welch's t-

316 test (garbage trucks: $\mathrm{p}=0.64$, PFI: $\mathrm{p}$-value $=0.65$ ). Size resolved PFI PN EFs, as well as a complete

317 discussion of the garbage truck plumes used as a control in this study, are provided in the 318 Supporting Information.

320 Size-resolved GDI PN EFs for each of the campaigns are shown in Figure 4. These size 321 distributions were bimodal, consistent with several previous studies ${ }^{10-13}$, and the distributions from 322 the 2014 and 2015 winter campaigns were broader than those measured in the spring and summer

3232014 campaigns. Further, the upper mode was larger in the winter; $100 \mathrm{~nm}$ in winter vs $40-55 \mathrm{~nm}$

324 in spring and summer campaigns, likely due to increased condensation in the colder outdoor 325 temperatures and limited nighttime mixing conditions. Comparing the PN EF size distributions 326 from the near-road $(15 \mathrm{~m})$ and the roadside $(1.5-3 \mathrm{~m})$ measurement sites, it was observed that 327 across all measurement campaigns there was a net increase in PN EF and growth in the mode 328 diameter in the lower sub-40 nm mode region. Additionally, the increase in sub-40 nm particles $32915 \mathrm{~m}$ from the roadway was less pronounced during the summer 2014 campaign, possibly due to 330 the competing effects of evaporation in the warmer weather. This is in contrast to the upper mode 331 region $(40-100 \mathrm{~nm})$, where the near-road PN EFs were higher between 3 and $15 \mathrm{~m}$ from the 
332 roadway for the spring and summer campaigns but with no net change in the shape of the

333 distribution. This could be affected by seasonal differences in background semi-volatile compound

334 concentrations; however, these were not measured and thus this finding remains unclear.

335 Thermodenuded particle size distributions (Supporting Information Figure S7) were generally

336 bimodal with modes at 10 and $25 \mathrm{~nm}$, suggesting the semi-volatile components within the exhaust

337 or in the background air may strongly influence the final measured size distribution.

339 Considering the sub-40 region separately there may be two possible effects on PN EFs: (1) rapid

340 growth of small particles below instrument detection limits $(<5 \mathrm{~nm})$ via condensation of low

341 volatility gases to form new sub-40 nm particles and (2) coagulation of particles resulting in

342 particle growth and a less distinct bimodality. The latter mechanism is unlikely due to the small

343 coagulation coefficient between two sub-6 $\mathrm{nm}$ particles; while these very small particles have high

344 velocities, the probability of collision is low due to their limited cross-sectional area. ${ }^{58}$ In order for

345 the former effect to be true, a substantial concentration of exhaust particles below the instrument

346 cut off $(6 \mathrm{~nm})$ are required as a core for condensational growth. A recent study demonstrated that

$3472 \mathrm{~nm}$ amorphous carbon particles are readily formed at flame temperatures in the GDI combustion

348 chamber ${ }^{59}$, potentially acting as condensation nuclei and influencing gas-particle partitioning.

350 Increasing PN EFs in the 15 m near-road region were not observed for the PFI vehicle, which is 351 also expected to produce low volatility organic vapours capable of condensing onto existing soot

352 cores. Here, we suggest two reasons for this observation: a lower concentration of soot cores from 353 the tailpipe of PFI vehicles and a volatility distribution of PFI vehicles shifted towards higher 354 vapour pressure compounds (i.e., more volatile). In GDI vehicles, there is less time for fuel 
355 vaporization and air-fuel mixing, resulting in a less homogeneous fuel charge (i.e., fuel rich

356 pockets in the combustion chamber) and greater liquid fuel impingement on cylinder surfaces

357 compared to PFI vehicles. ${ }^{60,61}$ These areas of rich combustion are expected to result in the

358 formation of incomplete combustion products including soot and SVOCs ${ }^{62}$. While May et al. ${ }^{63}$

359 conclude that all gasoline vehicles emit primary organic aerosol with a similar volatility

360 distribution, the GDI vehicle included in their study was excluded from the reported volatility

361 distribution due to contamination of the dynamic blanks, thus the differences in volatility

362 distribution between PFI and GDI vehicles remains unclear. In this study, comparing winter 2014

363 and spring 2014 near-road PN EFs, there was a statistically significant increase from spring to

364 winter of $125 \%$ for the GDI vehicle $(\mathrm{p}=0.022)$, while the observed increase in PN EF from the PFI

365 vehicle was not statistically significant $(\mathrm{p}=0.18)$. Assuming this increase is primarily due to

366 condensation, the larger relative increase with the GDI vehicle suggests a greater degree of gas -

367 particle partitioning for the GDI vehicle in the near-road region compared to PFI. In the Supporting

368 Information, the concentration of organic vapor needed to achieve the observed GDI PM growth

369 rates is explored; however, the mechanism for the observed near-road dynamics remains unclear.

370 As such, future studies of GDI PM particle formation and growth mechanisms are recommended

371 to better understand our findings.

\section{$373 \quad 3.4 \quad$ Laboratory and Real-World Comparison}

374 PN EFs measured in the real-world were observed to exceed those measured in the laboratory by

375 approximately an order of magnitude (Figure 2 vs. Figure 5). Measurements in real-world

376 environments are diluted naturally in the atmosphere, where the volatile fraction can contribute

377 significantly to the PN concentration. The large discrepancy between the real-world and laboratory 
378 particle number emissions has important regulatory implications, since the sub-23 nm fraction of

379 the PM is not considered in European regulations, but may have significant air quality implications

380 or contribute to the formation of secondary organic aerosol.

382 Removing the volatile fraction of the real-world exhaust $\mathrm{PM}$ with a thermodenuder $\left(\mathrm{T}=250^{\circ} \mathrm{C}\right)$

383 should result in PN EFs that can be directly compared to the laboratory, as the exhaust will have

384 undergone similar pretreatment. Comparing thermodenuded real-world PN EFs to the laboratory

385 PN EFs resulted in particle number emission factors that agreed with laboratory measurements

386 within approximately $30 \%$ (Figure 5). As the engine was operated at a simulated highway cruise

387 condition in the laboratory, PN EFs in the laboratory may be slightly higher due to the higher

388 engine load and speed as compared to driving in an urban environment.

390 Laboratory and real-world BC emission factors were also compared as an internal control for the

391 real-world-based method. Exhaust conditioning and meteorology are expected to have minimal

392 impacts on black carbon, which is atmospherically stable, and as such, laboratory and real-world

393 measurements should be in agreement. Black carbon (real-world) and elemental carbon

394 (laboratory) emission factors were also comparable (Figure 5); compared to the summer 2014

395 campaign, real-world BC EF agreed with the E10 laboratory elemental carbon emission factors

396 within $10 \%$. This is consistent with the requirement in Ontario that regular gasoline (87 anti-knock

397 index) contain at least 5\% (v/v) ethanol and with many suppliers providing fuel with up to $10 \%$

398 (v/v) ethanol. While differences between laboratory elemental carbon and real-world BC can be

399 affected by the thermal-optical and photoacoustic methods ${ }^{64,65}$, we used site-specific mass

400 absorption cross-section (MAC) values to ensure close agreement between the two methods. 


\section{$402 \quad 3.5 \quad$ Implications}

403 From this study, it can be concluded that particles in GDI vehicles have PN, BC, and BTEX EFs

404 in the upper end of the fleet distribution and the exhaust plumes exhibit dynamic behaviour in the

405 near-road $(15 \mathrm{~m})$ region, with increasing PN EFs at increasing distance from the roadway. This

406 suggests that as GDI vehicle market penetration increases, there may be negative impacts on local

407 air quality, especially in urban environments near roadways. The observed near-road PN dynamics

408 were unique to GDI vehicles, as the same effects were not observed for heavy-duty diesel garbage

409 trucks or a PFI-equipped vehicle. From comparing GDI vehicle size distributions at different

410 distances from the roadway, rapid particle growth of sub-5 nmcores due to condensation of low

411 volatility organic gasses is proposed to be the dominant growth mechanism in GDI vehicle exhaust.

412 Given the rapid integration of GDI-equipped vehicles, understanding the impacts of GDI vehicles

413 on local and regional air quality presents a significant measurement challenge, because exhaust

414 PN and BTEX concentrations were found to be strongly influenced by meteorological conditions.

415 Additionally, the current European regulatory practice for quantifying exhaust PN, which only

416 considers non-volatile PN larger than $23 \mathrm{~nm}$, appears to be ill-suited to this exhaust type; PN EFs

417 with no thermal pretreatment were approximately an order of magnitude larger than non-volatile

418 PN laboratory measurements. Furthermore, the dynamics investigated in this study were limited

419 to $15 \mathrm{~m}$ from the roadway. Understanding the fate of GDI vehicle exhaust beyond $15 \mathrm{~m}$ remains

420 an important research question, and the potential for GDI vehicle exhaust to form secondary

421 organic aerosol relative to PFI vehicle exhaust is currently unknown. Going forward, there is a

422 need to explore GDI emissions from more vehicles to better quantify the effect on vehicle fleet

423 emissions, and to understand the longer term behaviour of GDI vehicle exhaust in real-world

424 settings through more detailed experiments, aerosol aging studies, and micro-scale modelling. 
426 Funding for this study was provided by the Canadian Foundation for Innovation (CFI 19606) and

427 the Natural Sciences and Engineering Research Council (NSERC) Strategic Project Grant program

428 (STPGP 396488-10). N. Zimmerman's funding was provided by the NSERC Postgraduate

429 Scholarship. M. Ramos's funding was provided by the AUTO21 Network of Centres of Excellence

430 (Project D506-DMP). The authors thank C. Maikawa and A. Rodrigues for their assistance

431 monitoring the roadside instruments.

432

\section{SUPPORTING INFORMATION}

434 Further details on the study methodology, instrumentation and method validation, statistical

435 testing, tabulated emission factors, size distributions and an analyses of emissions growth 436 dynamics are provided.

\section{References}

439 (1) United States Department of Transportation. Final regulatory impact analysis, corporate average fuel economy for MY 2012-MY 2016 passenger cars and light trucks; Washington, D.C., 2010.

(2) United States Environmental Protection Agency. 2017 and later model year light-duty vehicle greenhouse gas emissions and corporate average fuel economy standards; final rule. Fed. Regist. 2012, 77 (199), 62624-63200.

(3) Zhao, F.; Lai, M. C.; Harrington, D. L. Automotive spark-ignited direct-injection gasoline engines. Prog. Energy Combust. Sci. 1999, 25 (5), 437-562.

(4) United States Environmental Protection Agency. Light-duty automotive technology, carbon dioxide emissions, and fuel economy trends : 1975 through 2014; 2014.

(5) United States Environmental Protection Agency. Final rulemaking to establish light-duty vehicle greenhouse gas emission standards and corporate average fuel economy 
standards; 2010.

(6) Graham, L. Chemical characterization of emissions from advanced technology light-duty vehicles. Atmos. Environ. 2005, 39 (13), 2385-2398.

Khalek, I. A.; Bougher, T.; Jetter, J. J. Particle emissions from a 2009 gasoline direct injection engine using different commercially available fuels. SAE Int. J. Fuels Lubr. 2010, 3 (2), 623-637.

(9) Maricq, M. M.; Szente, J. J.; Jahr, K. The impact of ethanol fuel blends on PM emissions from a light-duty GDI vehicle. Aerosol Sci. Technol. 2012, 46 (5), 576-583.

(10) Peckham, M. S.; Finch, A.; Campbell, B.; Price, P.; Davies, M. T. Study of particle number emissions from a turbocharged gasoline direct injection (GDI) engine including data from a fast-response particle size spectrometer. In SAE 2011 World Congress and Exhibition; 2011.

(11) Barone, T. L.; Storey, J. M. E.; Youngquist, A. D.; Szybist, J. P. An analysis of directinjection spark-ignition (DISI) soot morphology. Atmos. Environ. 2012, 49, 268-274.

(12) Sementa, P.; Maria Vaglieco, B.; Catapano, F. Thermodynamic and optical characterizations of a high performance GDI engine operating in homogeneous and stratified charge mixture conditions fueled with gasoline and bio-ethanol. Fuel 2012, 96, 204-219.

(13) Karjalainen, P.; Pirjola, L.; Heikkilä, J.; Lähde, T.; Tzamkiozis, T.; Ntziachristos, L.; Keskinen, J.; Rönkkö, T. Exhaust particles of modern gasoline vehicles: A laboratory and an on-road study. Atmos. Environ. 2014, 97, 262-270.

(14) Storey, J. M.; Barone, T.; Norman, K.; Lewis, S. Ethanol Blend Effects On Direct Injection Spark-Ignition Gasoline Vehicle Particulate Matter Emissions. SAE Int. J. Fuels Lubr. 2010, 3 (2), 650-659.

(15) Chan, T. W.; Meloche, E.; Kubsh, J.; Rosenblatt, D.; Brezny, R.; Rideout, G. Evaluation 
of a Gasoline Particulate Filter to Reduce Particle Emissions from a Gasoline Direct Injection Vehicle. SAE Int. J. Fuels Lubr. 2012, 5 (3), 1277-1290.

(16) Chen, L.; Stone, R.; Richardson, D. Effect of the valve timing and the coolant temperature on particulate emissions from a gasoline direct-injection engine fuelled with gasoline and with a gasoline-ethanol blend. Proc. Inst. Mech. Eng. Part D J. Automob. Eng. 2012, 226 (10), 1419-1430.

(17) Zhang, S.; McMahon, W. Particulate Emissions for LEV II Light-Duty Gasoline Direct Injection Vehicles. SAE Int. J. Fuels Lubr. 2012, 5 (2), 637-646.

(18) Sgro, L. A.; Sementa, P.; Vaglieco, B. M.; Rusciano, G.; D’Anna, A.; Minutolo, P.; D'Anna, A.; Minutolo, P. Investigating the origin of nuclei particles in GDI engine exhausts. Combust. Flame 2012, 159 (4), 1687-1692.

(19) Mathis, U.; Mohr, M.; Forss, A.-M. Comprehensive particle characterization of modern gasoline and diesel passenger cars at low ambient temperatures. Atmos. Environ. 2005, 39 (1), 107-117.

(20) United States Environmental Protection Agency. Analysis of particulate matter emissions from light-duty gasoline vehicles in Kansas City; 2008.

(21) Cadle, S. H.; Mulawa, P. A.; Hunsanger, E. C.; Nelson, K.; Ragazzi, R. A.; Barrett, R.; Gallagher, G. L.; Lawson, D. R.; Knapp, K. T.; Snow, R. Composition of light-duty motor vehicle exhaust particulate matter in the Denver, Colorado area. Environ. Sci. Technol. 1999, 33 (14), 2328-2339.

(22) Robinson, A. L.; Grieshop, A. P.; Donahue, N. M.; Hunt, S. W. Updating the conceptual model for fine particle mass emissions from combustion systems. J. Air Waste Manage. Assoc. 2010, 60 (10), 1204-1222.

(23) Storey, J. M. E.; Lewis, S.; Szybist, J. P.; Thomas, J.; Barone, T. L.; Eibl, M.; Nafziger, E.; Kaul, B. Novel characterization of GDI engine exhaust for gasoline and mid-level gasoline-alcohol blends. SAE Int. J. Fuels Lubr. 2014, 7 (2), 571-579.

(24) Uhrner, U.; Zallinger, M.; von Löwis, S.; Vehkamäki, H.; Wehner, B.; Stratmann, F.; Wiedensohler, A. Volatile nanoparticle formation and growth within a diluting diesel car exhaust. J. Air Waste Manage. Assoc. 2011, 61 (4), 399-408. 
(25) Olin, M.; Rönkkö, T.; Dal Maso, M. CFD modeling of a vehicle exhaust laboratory sampling system: sulfur-driven nucleation and growth in diluting diesel exhaust. Atmos. Chem. Phys. 2015, 15 (9), 5305-5323.

(26) Wang, Y. J.; Zhang, K. M. Coupled turbulence and aerosol dynamics modeling of vehicle exhaust plumes using the CTAG model. Atmos. Environ. 2012, 59, 284-293.

(27) Pirjola, L.; Karjalainen, P.; Heikkilä, J.; Saari, S.; Tzamkiozis, T.; Ntziachristos, L.; emitted by a modern gasoline direct injection passenger car. Environ. Sci. Technol. 2015, 49 (6), 3644-3652.

(28) Gentner, D.; Isaacman, G.; Worton, D. R.; Chan, A. W. H.; Dallmann, T. R.; Davis, L.; Liu, S.; Day, D. A.; Russell, L. M.; Wilson, K. R.; et al. Elucidating secondary organic aerosol from diesel and gasoline vehicles through detailed characterization of organic carbon emissions. Proc. Natl. Acad. Sci. 2012, 109 (45), 18318-18323.

(30) Nordin, E. Z.; Eriksson, a. C.; Roldin, P.; Nilsson, P. T.; Carlsson, J. E.; Kajos, M. K.; Hellén, H.; Wittbom, C.; Rissler, J.; Löndahl, J.; et al. Secondary organic aerosol formation from idling gasoline passenger vehicle emissions investigated in a smog chamber. Atmos. Chem. Phys. 2013, 13 (12), 6101-6116.

(31) Giechaskiel, B.; Chirico, R.; Decarlo, P. F.; Clairotte, M.; Adam, T.; Martini, G.; Heringa, M. F.; Richter, R.; Prevot, A. S. H.; Baltensperger, U.; et al. Evaluation of the particle measurement programme (PMP) protocol to remove the vehicles' exhaust aerosol volatile phase. Sci. Total Environ. 2010, 408 (21), 5106-5116.

(32) Wang, J. M.; Jeong, C.-H.; Zimmerman, N.; Healy, R. M.; Wang, D. K.; Ke, F.; Evans, G. J. Plume-based analysis of vehicle fleet air pollutant emissions and the contribution from high emitters. Atmos. Meas. Tech. 2015, 8 (8), 3263-3275.

(33) Rönkkö, T.; Pirjola, L.; Ntziachristos, L.; Heikkilä, J.; Karjalainen, P.; Hillamo, R.; Keskinen, J. Vehicle engines produce exhaust nanoparticles even when not fueled. Environ. Sci. Technol. 2014, 48 (3), 2043-2050.

(34) Ban-Weiss, G. A.; Lunden, M. M.; Kirchstetter, T. W.; Harley, R. A. Size-resolved particle number and volume emission factors for on-road gasoline and diesel motor 
vehicles. J. Aerosol Sci. 2010, 41 (1), 5-12.

(35) Zimmerman, N.; Godri Pollitt, K. J.; Jeong, C.-H.; Wang, J. M.; Jung, T.; Cooper, J. M.; Wallace, J. S.; Evans, G. J. Comparison of three nanoparticle sizing instruments: The influence of particle morphology. Atmos. Environ. 2014, 86, 140-147.

(36) Zimmerman, N.; Jeong, C.-H.; Wang, J. M.; Ramos, M.; Wallace, J. S.; Evans, G. J. A source-independent empirical correction procedure for the Fast Mobility and Engine Exhaust Particle Sizers. Atmos. Environ. 2015, 100, 178-184.

(38) Ranjan, M.; Presto, A. A.; May, A. A.; Robinson, A. L. Temperature dependence of gasparticle partitioning of primary organic aerosol emissions from a small diesel engine. Aerosol Sci. Technol. 2012, 46 (1), 13-21.

(39) Charron, A.; Harrison, R. M. Primary particle formation from vehicle emissions during exhaust dilution in the roadside atmosphere. Atmos. Environ. 2003, 37 (29), 4109-4119.

(40) Janhäll, S.; Molnar, P.; Hallquist, M. Traffic emission factors of ultrafine particles: effects from ambient air. J. Environ. Monit. 2012, 14 (9), 2488-2496.

(41) He, X.; Ratcliff, M. A.; Zigler, B. T. Effects of gasoline direct injection engine operating parameters on particle number emissions. Energy \& Fuels 2012, 26 (4), 2014-2027.

(42) Lough, G. C.; Schauer, J. J.; Lonneman, W. A.; Allen, M. K. Summer and Winter Nonmethane hydrocarbon emissions from on-road motor vehicles in the midwestern United States. J. Air Waste Manage. Assoc. 2005, 55 (5), 629-646.

(43) White, M. L.; Russo, R. S.; Zhou, Y.; Ambrose, J. L.; Haase, K.; Frinak, E. K.; Varner, R. K.; Wingenter, O. W.; Mao, H.; Talbot, R.; et al. Are biogenic emissions a significant source of summertime atmospheric toluene in rural Northeastern United States? Atmos. Chem. Phys. Discuss. 2008, 8 (3), 12283-12311.

(44) Ramos, M. Sources of Particulate Matter Emissions Variability from a Gasoline Direct Injection Engine, MASc. Thesis, University of Toronto, Toronto, Canada, 2014.

(45) Karavalakis, G.; Short, D. Z.; Vu, D.; Russell, R. L.; Hajbabaei, M.; Asa-Awuku, A.; Durbin, T. D. Evaluating the effects of aromatics content in gasoline on gaseous and 
particulate matter emissions from SI-PFI and SI-DI vehicles. Environ. Sci. Technol. 2015, 49, 7021-7031.

(46) Forestieri, S. D.; Collier, S.; Kuwayama, T.; Zhang, Q.; Kleeman, M. J.; Cappa, C. D. Real-time black carbon emission factor measurements from light duty vehicles. Environ. Sci. Technol. 2013, 47 (22), 13104-13112.

(47) Park, S. S.; Kozawa, K.; Fruin, S.; Mara, S.; Hsu, Y. K.; Jakober, C.; Winer, A.; Herner, J. Emission factors for high-emitting vehicles based on on-road measurements of individual vehicle exhaust with a mobile measurement platform. J. Air Waste Manag. Assoc. 2011, 61 (10), 1046-1056.

(48) Hudda, N.; Fruin, S.; Delfino, R. J.; Sioutas, C. Efficient determination of vehicle emission factors by fuel use category using on-road measurements: downward trends on Los Angeles freight corridor I-710. Atmos. Chem. Phys. 2013, 13 (1), 347-357.

(49) Gëller, M. D.; Sardar, S. B.; Phuleria, H.; Fine, P. M.; Sioutas, C. Measurements of particle number and mass concentrations and size distributions in a tunnel environment. Environ. Sci. Technol. 2005, 39 (22), 8653-8663.

(50) Westerdahl, D.; Wang, X.; Pan, X.; Zhang, K. M. Characterization of on-road vehicle emission factors and microenvironmental air quality in Beijing, China. Atmos. Environ. 2009, 43 (3), 697-705.

(51) Liggio, J.; Gordon, M.; Smallwood, G.; Li, S.-M.; Stroud, C.; Staebler, R.; Lu, G.; Lee, P.; Taylor, B.; Brook, J. R. Are emissions of black carbon from gasoline vehicles underestimated? Insights from near and on-road measurements. Environ. Sci. Technol. 2012, 46 (9), 4819-4828.

(52) Storey, J. M. E.; Barone, T. L.; Thomas, J. F.; Huff, S. P. Exhaust particle characterization for lean and stoichiometric DI vehicles operating on ethanol-gasoline blends. In SAE Technical Papers; 2012.

(53) Chen, L.; Braisher, M.; Crossley, A.; Stone, R.; Richardson, D. The Influence of Ethanol Blends on Particulate Matter Emissions from Gasoline Direct Injection Engines. In SAE Technical Papers; 2010.

(54) Bruehlmann, S.; Forss, A.-M.; Steffen, D.; Heeb, N. V. Benzene: a secondary pollutant formed in the three-way catalyst. Environ. Sci. Technol. 2005, 39 (1), 331-338. 
(55) U.S. Department of Energy. Gas Mileage of 2013 Ford Focus https://www.fueleconomy.gov/feg/bymodel/2013_Ford_Focus.shtml.

(56) U.S. Department of Energy. Gas Mileage of 2004 Ford Focus https://www.fueleconomy.gov/feg/bymodel/2004_Ford_Focus.shtml.

(57) U.S. Department of Energy. Gas Mileage of 2008 Ford Focus

(59) Sgro, L. A.; Sementa, P.; Vaglieco, B. M.; Rusciano, G.; D’Anna, A.; Minutolo, P. Investigating the origin of nuclei particles in GDI engine exhausts. Combust. Flame 2012, 159 (4), 1687-1692.

(60) Stojkovic, B. D.; Fansler, T. D.; Drake, M. C.; Sick, V. High-speed imaging of OH* and soot temperature and concentration in a stratified-charge direct-injection gasoline engine. Proc. Combust. Inst. 2005, 30 II (2), 2657-2665.

(61) Velji, A.; Yeom, K.; Wagner, U.; Spicher, U.; Rossbach, M.; Suntz, R.; Bockhorn, H. Investigations of the formation and oxidation of soot inside a direct injection spark ignition engine using advanced laser-techniques. SAE Tech. Pap. 2010, No. 2010-010352 .

(62) Zimmerman, N.; Pant, P.; Jeong, C.-H.; Rais, K.; Delgado-Saborit, J. M.; Wallace, J. S.; Evans, G. J.; Brook, J. R.; Pollitt, K. J. Carbonaceous aerosol sampling of gasoline direct injection engine exhaust with an integrated organic gas and particle sampler. Sci. Total Environ. 2016 in preparation.

(63) May, A. A.; Presto, A. A.; Hennigan, C. J.; Nguyen, N. T.; Gordon, T. D.; Robinson, A. L. Gas-particle partitioning of primary organic aerosol emissions: (1) Gasoline vehicle exhaust. Atmos. Environ. 2013, 77, 128-139.

(64) Kamboures, M. A.; Hu, S.; Yu, Y.; Sandoval, J.; Rieger, P.; Huang, S.-M.; Zhang, S.; Dzhema, I.; Huo, D.; Ayala, A.; et al. Black carbon emissions in gasoline vehicle exhaust: A measurement and instrument comparison. J. Air Waste Manage. Assoc. 2013, 63 (8), 886-901. 
692 (65) Yelverton, T. L. B.; Hays, M. D.; Gullett, B. K.; Linak, W. P. Black carbon measurements of flame-generated soot as determined by optical, thermal-optical, direct absorption, and 

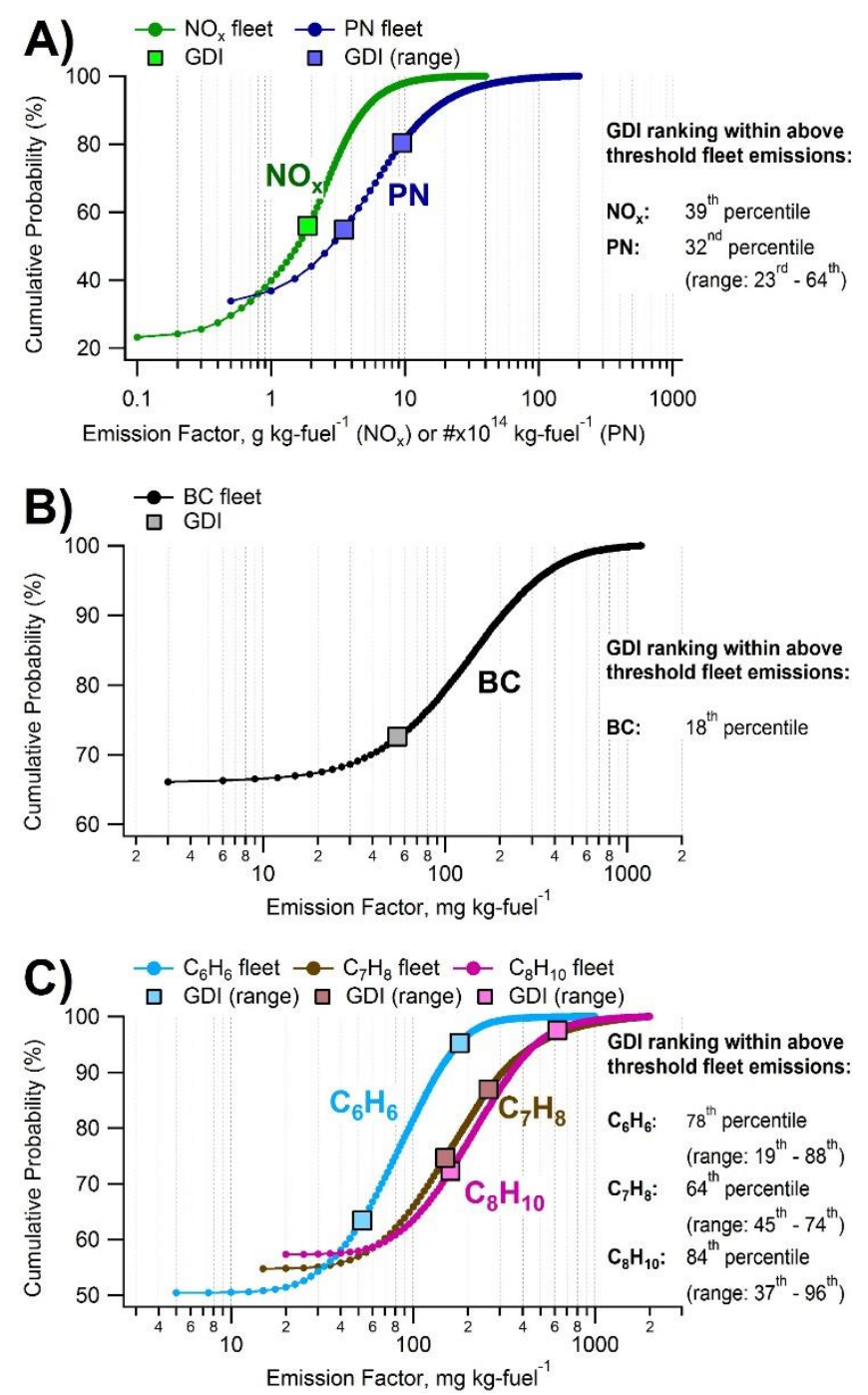

Emission Factor, $\mathrm{mg} \mathrm{kg-fuel}^{-1}$

Figure 1: Cumulative probability distribution of Toronto fleet emission factors for PN and NOx (A), BC (B) and for VOCs (C) from Wang et al. ${ }^{32}$. The starting point of the distribution represents the fraction of below detection plumes. Overlaid on the fleet distributions are the GDI EFs from this study. To the right of each distribution the GDI ranking within the above threshold emissions (i.e., rank on the curve). If statistically significant differences between the seasons were observed, two markers indicating the range are shown, otherwise one average GDI EF is shown. 


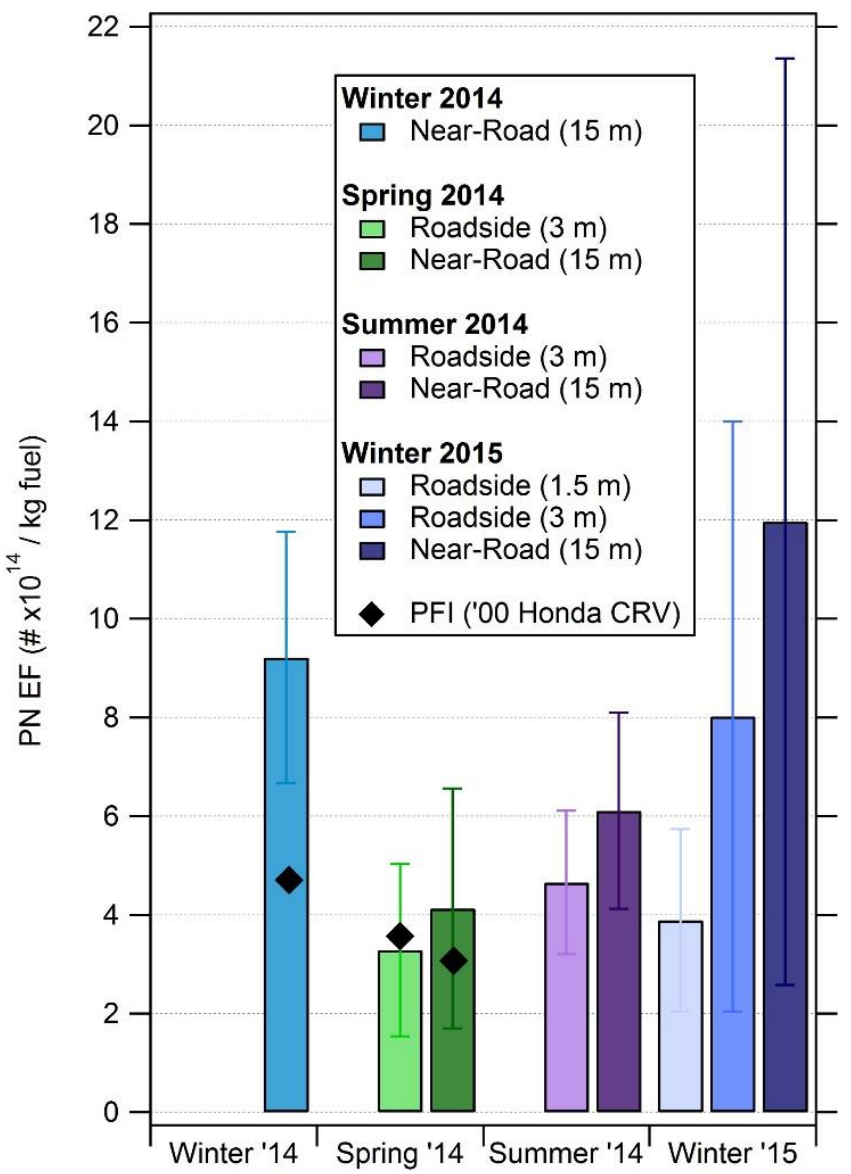

707 Figure 2: Average GDI particle number (PN) emission factors measured by the $3788 \mathrm{CPC}(>3 \mathrm{~nm})$ at the near-road 708 $(15 \mathrm{~m})$ and roadside $(1.5-3 \mathrm{~m})$ sites during the four measurement campaigns with $95 \%$ confidence intervals. 


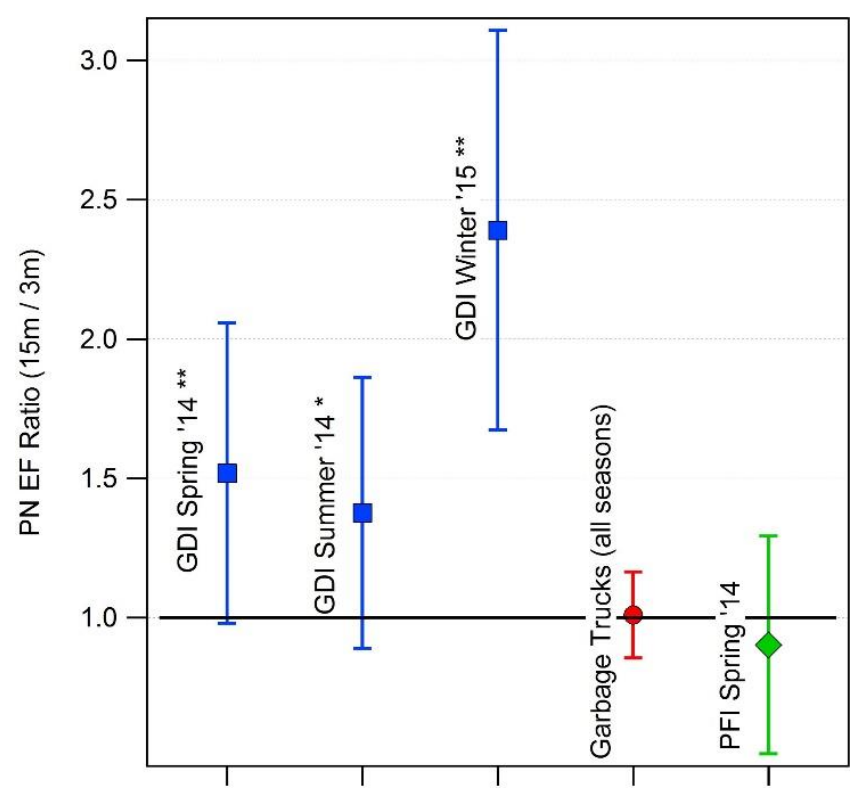

710 Figure 3: Average ratio of particle number emission factors measured by the $3788 \mathrm{CPC}(>3 \mathrm{~nm})$ at the near-road (15 $711 \mathrm{~m})$ and roadside $(3 \mathrm{~m})$ site on a plume-by-plume basis for the spring 2014, summer 2014, and winter 2015 campaigns 712 (with 95\% confidence intervals). Results were compared to diesel garbage truck plumes measured across the 713 measurement campaigns and PFI plumes measured in the spring 2014 campaign. Asterisks indicate p-values from a 714 one sample t-test with the null hypothesis $\mu_{\mathrm{o}}=1$. **: $\mathrm{p}<0.05$, *: $\mathrm{p}<0.1$ 

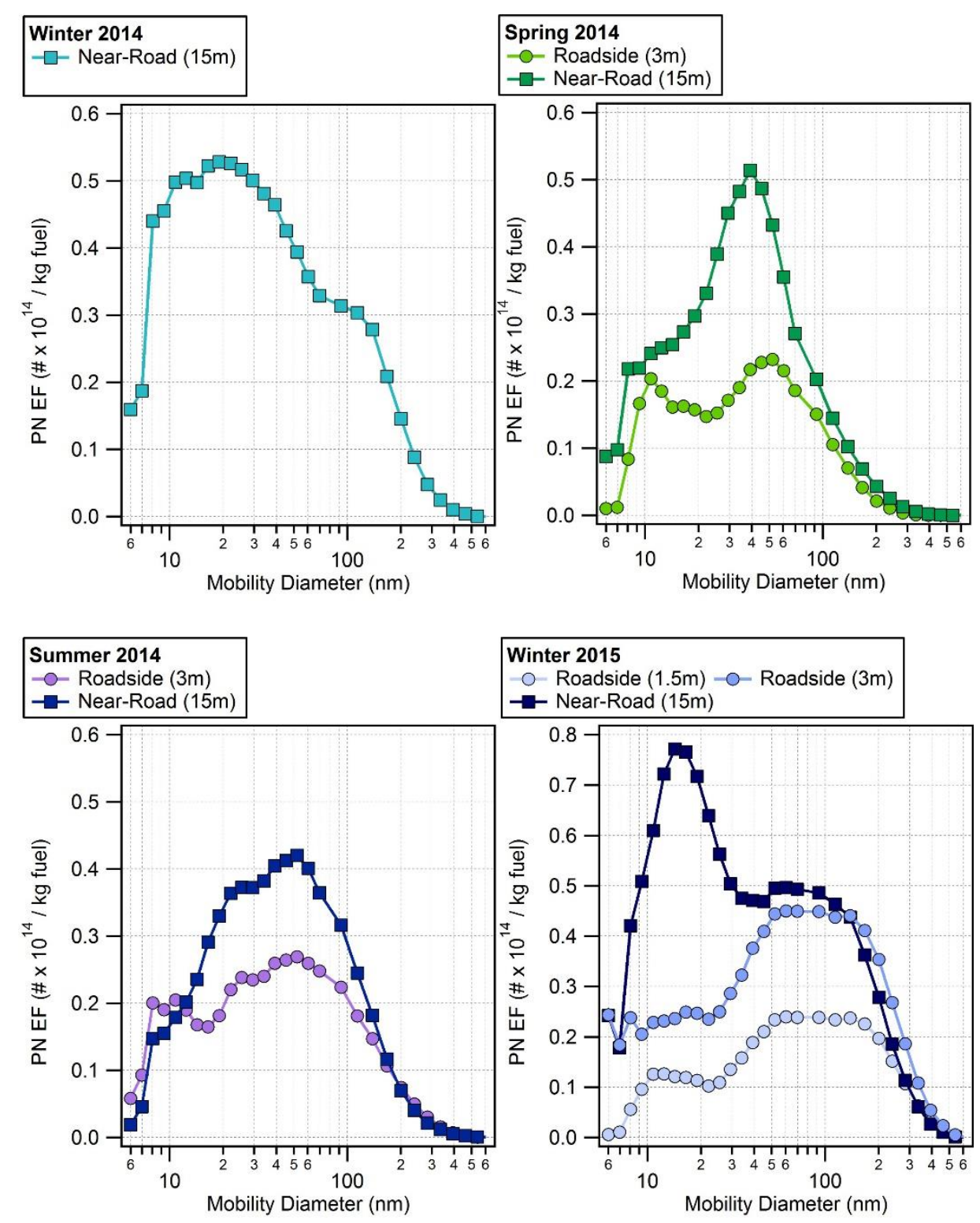

716 Figure 4: Size-resolved PN EFs at the near-road (15 m) and roadside $(1.5-3 \mathrm{~m})$ sites. 


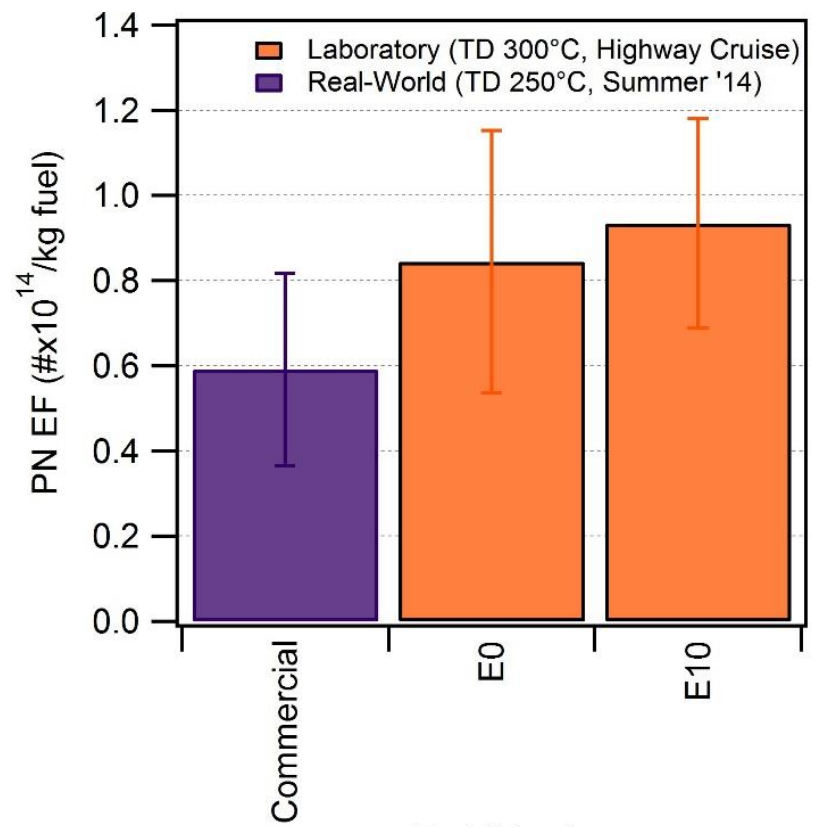

Fuel Blend

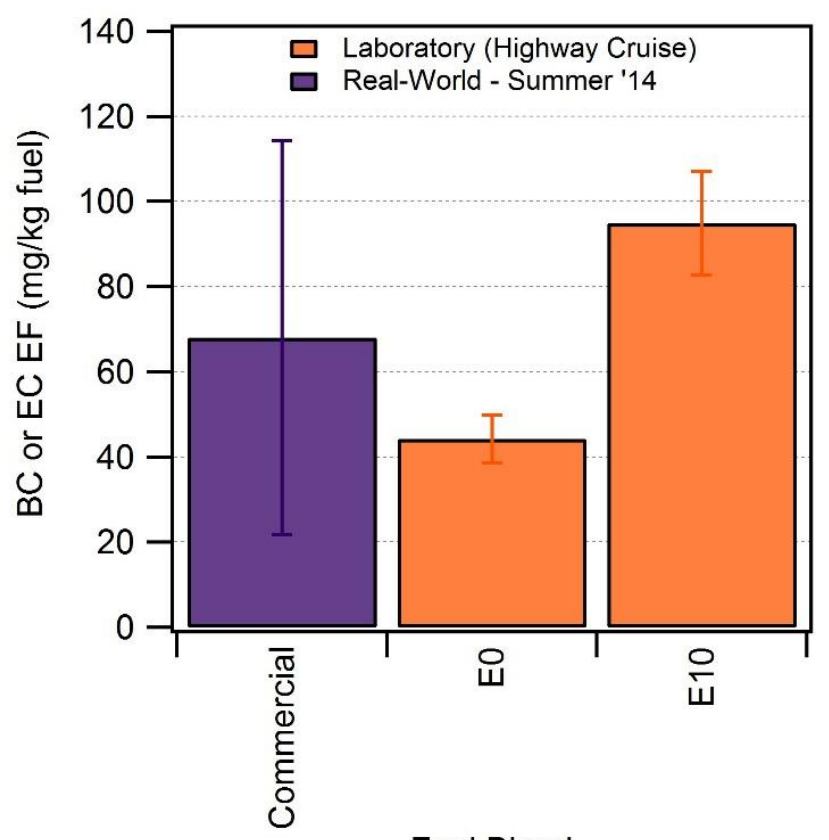

Fuel Blend

719 Figure 5: Average particle number emission factors measured in the laboratory for E0-E10 summer-grade fuels (orange) during a simulated highway cruise operation (diluter $\mathrm{T}=300^{\circ} \mathrm{C}$ ) (EEPS 3090, > $6 \mathrm{~nm}$ ) and average thermodenuded $\left(250^{\circ} \mathrm{C}\right)$ particle number emission factor (CPC 3788, >3 nm) measured during the real-world in summer 2014 (purple) (left panel), and average elemental carbon (EC) emission factors measured in the laboratory for E0-E10 fuels (orange) during a simulated highway cruise operation and average black carbon (BC) emission factors during the real-world in summer 2014 (purple) (left panel). 